\title{
EFICIENCIA DO HERBICIDA OXYFLUORFEN, QUANDO VEICULADO AO PAPEL, NO CONTROLE DE ALGUMAS ESPECIES DANINHAS
}

\author{
ALEXANDRE J. BEZUTTE ${ }^{2}$, FABIO CALEGARE ${ }^{2}$ PEDRO L.C.A. ALVES ${ }^{2}$ e ROBINSON A. \\ PITELLI ${ }^{2}$
}

\begin{abstract}
Com o objetivo de encontrar um método alternativo de aplicação de herbicidas, estudou-se a eficiência do oxyfluorfen aplicado em três doses (0, 480 e $960 \mathrm{~g} / \mathrm{ha})$ sob duas formas (pulverizado e veiculado em folha de papel) no controle em pré-emergência de Bidens pilosa, Desmodium tortuosum, Eleusine indica, Sida rhombifolia, Amaranthus retroflexus, Acanthospermum hispidum e Digitaria horizontalis. A pulverização do oxyfluorfen foi realizada com o auxílio de um pulverizador, e sua veiculação foi feita através da determinação prévia da capacidade de embebição do papel. Obteve-se a concentração necessária da calda quando o papel atingiu completa embebição e então, escorrido o excesso, foi posto a secar na sombra. $\mathrm{O}$ delineamento experimental foi o inteiramente casualizado, com cinco repetições. Foram realizadas avaliações aos 30, 45 e 60 dias após a
\end{abstract}

RESUMO

aplicação (DAA), e os resultados indicaram que os métodos de aplicação utilizados, assim como as doses, apresentaram excelente controle de B. pilosa, D. tortuosum, E. indica, $S$. rhombifolia, D. horizontalis e A. retroflexus até 60 DAA, reduzindo tanto a densidade como o acúmulo de matéria seca. Quanto ao A. hispidum, ambos os métodos e doses não proporcionaram bom controle. Foi observado também que o papel utilizado como veículo do oxyfluorfen proporcionou redução na densidade de $B$. pilosa, E. indica, D. horizontalis $e$ A. retroflexus e promoveu a germinação de $S$. rhombifolia $e A$. hispidum quando da avaliação aos 60 DAA. Estes resultados demonstram a viabilidade de utilização de papel como veículo de aplicação do oxyfluorfen. ninhas.

Palavras-chave: Tecnologia de aplicação, plantas da-

\section{ABSTRACT}

\section{Effect of the herbicide oxyfluorfen using paper as a vehicle on the weed control}

A greenhouse assay was conducted to evaluate an alternative method for applying oxyfluorfen to control annual weeds. The experiment was in a $3 \times 2$ factorial, in a completely randomized design, with three replications. The factors were: three doses of oxyfluorfen $(0,480$ and $960 \mathrm{~g} / \mathrm{ha})$ and two methods to apply the herbicide to the soil surface (sprayed or soaked in paper sheet). The weeds studied were Bidens pilosa, Desmodium tortuosum, Eleusine indica, Sida rhombifolia, Amaranthus retroflexus, Acanthospermum hispidum and Digitaria horizontalis. Weed control was evaluated at 30, 45 and 60 days after the herbicide application (DAA). The application methods, as well as the doses

1 Recebido para publicação em 20/01/94 e na forma revisada em 25/05/95. 2 FCAVJ/UNESP, Rod. Carlos Tonanni, km 5, Jaboticabal, SP 14870-000 showed excellent control of B. pilosa, D. tortuosum, E. indica, S. rhombifolia, D. horizontalis, and A. retroflexus up to 60 DAA, reducing the density as well as the dry matter surplus. On A. hispidum, both methods and doses did not show good control. It was also observed that the paper utilized as the oxyfluorfen vehicle produced density reduction in B. pilosa, E. indica, D. horizontalis and A. retroflexus and induced the germination of S. rhombifolia and A. hispidum when evaluated at 60 DAA. These results demonstrated the viability of paper as the oxyfluorfen application vehicle.

Additional index words: Application technology, weeds.

Planta Daninha, v. 13, n. 1, 1995. 


\section{INTRODUÇÃO}

A preocupação com o ambiente e o elevado custo dos herbicidaS, para o efetivo controle das plantas invasoras de ecossistesmas agrícolas, tem levado pesquisadores a buscarem alternativascom menores custos e riscos ao ambiente.

Prudente \& Matuo (1985) afirmam que o método de pulverização tratorizada tradicional, apesar de proporcionar bons resultados no controle das plantas invasoras, apresenta um alto custo operacional, por utilizar combustível, máquinas e implementos caros, que requerem manutenção e substituição de peças. Além do elevado custo operacional os autores citam ainda como grande problema deste método de aplicação, a contaminação do ambiente com grande volume de herbicidas e água diluente por área. Como alternativa, os autores apresentam o método que emprega o uso de pavios de corda ("rape wick"), que proporciona baixos custos de aplicação, menores riscos ao ambiente e bom desempenho no controle das plantas invasoras.

Moreira (1990), em outro trabalho, apresenta como alternativa à pulverização tradicional a veiculação de herbicidas (pendimethalin e oxyfluorfen) na cobertura morta, no caso, a palha de arroz, com a finalidade de promover o controle das plantas invasoras em culturas olerícolas. $\mathrm{O}$ autor constatou que a veiculação do oxyfluorfen na palha de arroz proporcionou um efetivo controle sobre as espécies invasoras, não diferenciando da aplicação na mesma dosagem sob a forma de pulverização. Já no caso do pendimethalin, o produto veiculado na palha de arroz aumentou sua eficiência e o tempo de atividade em relação à mesma dosagem aplicada em pulverização.

Uma das características do oxyfluorfen, é suaadsorção total pelas partículas do solo nas camadas mais superficiais, o que, associado ao fato de ser praticamente insolúvel em água, o toma altamente resistente à lixiviação e à lavagem. A veiculação deste herbicida em superfícies de cor branca e/ou absorvente deverá provavelmente minimizar as perdas do produto por fotólise e por evaporação, que são os principais fatores envolvidos na degradação do oxyfluorfen e, consequentemente, na sua persistência. Além disso, a veiculação do produto proporciona baixos custos, pois dispensa a utilização de equipamentos caros e sofisticados; facilita a aplicação e aumenta o tempo de atividade do produto, resultando em uma relação custo/beneficio mais rentável, e causa menores danos ao ambiente, pois o herbicida será depositado somente na área de interesse, eliminando assim a deriva.

Dessa forma, o objetivo deste trabalho foi o de explorar estas características do oxyfluorfen, visando a apresentar uma nova e eficiente alternativa de aplicação de herbicidas, ou seja, a veiculação doproduto em papel absorvente.

\section{MATERIAL E MÉTODOS}

O experimento foi conduzido sob condições de casadevegetação, no Departamento de Biologia Aplicada à Agropecuária da Faculdade de Ciências Agrárias e Veterinárias / UNESP, Campus de Jaboticabal, SP.

O substrato utilizado foi obtido pela mistura de $30 \%$ de areia de rio lavada e esterilizada, com $70 \%$ de solo coletado da camada arável (A1-A2) de um Latossolo VermelhoEscuro, distrófico, A moderado, de textura média. O solo, antes de ser misturado, foi seco à sombra e peneirado em tamis de $5 \mathrm{~mm}$ de abertura. $\mathrm{O}$ substrato foi acondicionado em bandejas plásticas de $36 \mathrm{~cm}$ de comprimento por $26 \mathrm{~cm}$ de largura e $7 \mathrm{~cm}$ de altura, totalizando 6,5 litros de capacidade.

A infestação de plantas daninhas foi induzida, semeando-se em cada uma das bandejas um total de 15,0 g de propágulos das seguintes espécies, sendo apresentados, pela ordem, o nome científico, o nome popular e o código internacional de cada uma delas(Kissmann, 1992):

\section{MONOCOTILEDÔNEAS}

- Digitaria horizontalis (Capim-colchão) - DIGHO

- Eleusine indica (Capim-pé-de-galinha) - ELEIN

$1,5 \mathrm{~g}$

$2,0 \mathrm{~g}$

\section{DICOTILEDÔNEAS}

- Sida rhombifolia (Guanxuma) - SIDRH

- Amaranthus retroflexus (Caruru) - AMARE

$1,5 \mathrm{~g}$

- Acanthospermum hispidum (Carrapicho-de-carnei-

ro) - ACNHI

- Desmodium tortuosum (Ca rrapicho-beiço-de-boi) DESTO

- Bidens pilosa (Picão-preto) - BIDPI

$1,5 \mathrm{~g}$

$2,0 \mathrm{~g}$ $5,0 \mathrm{~g}$ $1,5 \mathrm{~g}$

Após a semeadura, as bandejas foram umedecidas e submetidas aos tratamentos. Estes constaram da aplicação em pré-emergência do herbicida oxyfluorfen nas duas formas (pulverizado e veiculado em papel), em três doses 0, 480 e 960 $\mathrm{g} / \mathrm{ha}$, totalizando seis tratamentos.

O oxyfluorfen utilizado no experimento possui nome comercial Goal BR e é apresentado na formulação de concentrado emulsionável, contendo $240 \mathrm{~g} / 1$ de ingrediente ativo (i.a.).

O experimento foi do tipo fatorial $3 \times 2$, inteiramente casualizado, com cinco repetições.

O material utilizado como veículo para o oxyfluorfen foi folha de papel de filtro qualitativo. Para os cálculos referentes a dose do herbicida veiculado no papel, determinouse inicialmente a capacidade de embebição do papel $(0,0203$ $\mathrm{g}$ água $/ \mathrm{cm}^{2}$ ) e, à partir desta foi feito o cálculo da concentração da fomulação comercial do herbicida na calda de embebição do papel. Após a embebição por uma hora, as folhas de papel com dimensões iguais às da área da bandeja foram postas a secar à sombra, quando então foram colocadas sobre a superfície do substrato (16/12/91).

A aplicação direta do oxyfluorfen foi realizada com auxílio de um pulverizador costal sob pressão constante (CO2) de $35 \mathrm{lb} / \mathrm{po}^{2}$, munido de barra com dois bicos Albus Verde espaçados de $50 \mathrm{~cm}$, e regulado para um gasto de calda de 250 1/ha. A pulverização foi realizada no dia 16/12/91, com início às 15:30 horas e término às 15:50 horas, ocasião em que não havia vento, com céu parcialmente nublado (5/8), temperatura do ar em $33^{\circ} \mathrm{C}$ e do substrato $(5 \mathrm{~cm})$ a $40^{\circ} \mathrm{C}$. A umidade relativa do ar era de $68 \%$ e o substrato encontrava-se úmido.

As avaliações nas densidades populacionais da comunidade infestante foram realizadas aos 30, 45, e 60 dias após a aplicação (DAA) do oxyfluorfen. Nas duas primeiras avaliações foram realizadas contagens das plantas por espécie e na ultima avaliação, além da contagem, foi obtido o peso da 
matéria seca (g/caixa) das plantas através de secagem do material em estufa com circulação forçada de ar $\left(70-80^{\circ} \mathrm{C}\right)$ por 96 horas.

\section{RESULTADOS E DISCUSÃO}

Observou-se que a colocação do papel sobre o solo reduziu a densidade de picão-preto (BIDPI) e do capimcolchão (DIGHO) até aos 45 dias após a aplicação (Tabelas 1 e 2). Em virtude disso, não se constatou efeito das doses do produto, quando este foi veicul ado no papel. Mas quando foram pulverizadas as doses de 480 e $960 \mathrm{~g} / \mathrm{ha}$, reduziu-se igualmente a densidade destas espécies. Aos 60 dias após a aplicação (Tabela 3), não se observaram mais interações entre doses e métodos de aplicação para estas espécies. Só foi constatado efeito de doses onde as doses de 480 e 960 $\mathrm{g} / \mathrm{ha}$ reduziram de modo parecido a densidade destas espécies, independente do método de aplicação. O mesmo efeito foi observado no peso da matéria seca da parte aérea destas plantas, avaliadas aos 60 DAA (Tabela 4).

Com relação ao carrapicho-beiço-de-boi (DESTO) e caruru (AMARE) observou-se até 60 DAA apenas efeito das doses do oxyfluorfen, que reduziram a densidade destas

TABELA 1 - Efeitos de doses de oxyfluorfen em dois métodos de aplicaçāo sobre a densidade ${ }^{(1)}$ de plantas de BIDPI, DESTO, ELEIN, DIGHO, SIDRH, AMARE, e ACNHI, avaliadas aos 30 DAA. Jaboticabal, 1991.

\begin{tabular}{|c|c|c|c|c|c|c|}
\hline \multirow{2}{*}{ Espécies } & \multirow{2}{*}{$\begin{array}{c}\text { Doses (D) } \\
(\mathrm{g} / \mathrm{ha})\end{array}$} & \multicolumn{2}{|c|}{ Método de Aplicação (MA) } & \multirow{2}{*}{ Média } & \multicolumn{2}{|c|}{ Valores } \\
\hline & & Pulverizado & Veiculado & & $\mathbf{F}$ & $\mathrm{CV}(\%)$ \\
\hline \multirow{4}{*}{ BIDPI } & 0 & $5,17 \mathrm{Aa}^{(2)}$ & $3,08 \mathrm{Ba}$ & (MA) & $6,81^{*}$ & \\
\hline & 480 & $2,51 \mathrm{Ab}$ & $2,58 \mathrm{Aa}$ & $2,54 \quad$ (D) & $15,75^{* *}$ & \\
\hline & 960 & $2,44 \mathrm{Ab}$ & $2,24 \mathrm{Aa}$ & 2,34 (MAxD) & $5,65^{* *}$ & \\
\hline & Média & 3,37 & 2,63 & - & & 25,92 \\
\hline \multirow{4}{*}{ DESTO } & 0 & - & - & 4,83 a $\quad(M A)$ & $3,13^{\mathrm{NS}}$ & \\
\hline & 480 & - & - & $2,30 \mathrm{~b} \quad(\mathrm{D})$ & $10,57^{* *}$ & \\
\hline & 960 & - & - & $2,30 \mathrm{~b}(\mathrm{MAxD})$ & $2,85^{\mathrm{NS}}$ & \\
\hline & Média & $3,60 \mathrm{~A}$ & $2,68 \mathrm{~A}$ & & & 45,22 \\
\hline \multirow{4}{*}{ ELEIN } & 0 & $12,82 \mathrm{Aa}$ & $7,16 \mathrm{Ba}$ & 9,99 & $27,64^{* *}$ & \\
\hline & 480 & $2,24 \mathrm{Ab}$ & $2,24 \mathrm{Ab}$ & $2,24 \quad$ (D) & $208,25 *$ & \\
\hline & 960 & $2,24 \mathrm{Ab}$ & $2,24 \mathrm{Ab}$ & 2,24 (MAxD) & $27,64^{* *}$ & \\
\hline & Média & 5,76 & 3,88 & - & & 20,35 \\
\hline \multirow{3}{*}{ DIGHO } & 0 & $2,91 \mathrm{Aa}$ & $2,36 \mathrm{Ba}$ & (MA) & $7,17^{\circ}$ & \\
\hline & 480 & $2,24 \mathrm{Ab}$ & $2,24 \mathrm{Aa}$ & $2,24 \quad$ (D) & $15,18 *$ & \\
\hline & 960 & $2,24 \mathrm{Ab}$ & $2,24 \mathrm{Aa}$ & 2,24 (MAxD) & $7,17^{* *}$ & \\
\hline \multirow{5}{*}{ SIDRH } & Média & 2,46 & 2,28 & - & & 7,88 \\
\hline & 0 & $4,56 \mathrm{Aa}$ & $3,54 \mathrm{Ba}$ & (MA) & $4,76^{\circ}$ & \\
\hline & 480 & $2,24 \mathrm{Ab}$ & $2,24 \mathrm{Ab}$ & $2,24 \quad$ (D) & $60,77^{* *}$ & \\
\hline & 960 & $2,24 \mathrm{Ab}$ & $2,24 \mathrm{Ab}$ & 2,24 (MAxD) & $4,76^{\circ}$ & \\
\hline & Média & 3,01 & 2,67 & - & & 14,96 \\
\hline \multirow{3}{*}{ AMARE } & 0 & - & - & 5,51 a $\quad(M A)$ & $2,13^{N S}$ & \\
\hline & 480 & - & - & $2,24 \mathrm{~b} \quad$ (D) & $9,68^{\circ}$ & \\
\hline & 960 & - & - & $2,24 \mathrm{~b}(\mathrm{MAxD})$ & $2,13^{\mathrm{NS}}$ & \\
\hline \multirow{5}{*}{$\mathrm{ACNHI}$} & Média & $3,84 \mathrm{~A}$ & $2,82 \mathrm{~A}$ & & & 57,74 \\
\hline & 0 & - & - & 2,65 a $\quad(M A)$ & $0,48^{\text {NS }}$ & \\
\hline & 480 & - & - & $2,24 \mathrm{~b} \quad$ (D) & $19,05^{* *}$ & \\
\hline & 960 & - & $\cdot$ & $2,24 \mathrm{~b}(\mathrm{MAxD})$ & $0,48^{\mathrm{NS}}$ & \\
\hline & Média & $2,35 \mathrm{~A}$ & $2,46 \mathrm{~A}$ & - & & 7,30 \\
\hline
\end{tabular}

(1) Dados transformados para $\sqrt{(\mathrm{X}+0,5)}$.

(2) Médias com a mesma letra năo diferem entre sí pelo teste de Tukey a $5 \%$ de probabilidade, sendo que letras minúsculas, comparam as doses e as maiúsculas comparam os métodos de aplicaçấo. 
TABELA 2 - Efeito de doses de oxyfluorfen em dois métodos de aplicação, sobre a densidade ${ }^{(1)}$ de plantas de BIDPI, DESTO, ELEIN, DIGHO, SIDRH, AMARE, e ACNHI, avaliadas aos 45 DAA. Jaboticabal, 1991.

\begin{tabular}{|c|c|c|c|c|c|c|}
\hline \multirow{2}{*}{ Espécies } & \multirow{2}{*}{$\begin{array}{c}\text { Doses (D) } \\
(\mathrm{g} / \mathrm{ha})\end{array}$} & \multicolumn{2}{|c|}{ Método de Aplicação (MA) } & \multirow{2}{*}{ Média } & \multicolumn{2}{|c|}{ Valores } \\
\hline & & Pulverizado & Veiculado & & $\mathbf{F}$ & $\mathrm{CV}(\%)$ \\
\hline \multirow{4}{*}{ BIDPI } & 0 & $4,95 \mathrm{Aa}^{(2)}$ & $3,12 \mathrm{Ba}$ & (MA) & $2,36^{\mathrm{NS}}$ & \\
\hline & 480 & $2,52 \mathrm{Ab}$ & 3,05 Aa & $2,78 \quad$ (D) & $11,81^{* *}$ & \\
\hline & 960 & $2,40 \mathrm{Ab}$ & $2,36 \mathrm{Aa}$ & $2,38 \quad$ (MAxD) & $6,01^{* *}$ & \\
\hline & Média & 3,29 & 2,84 & - & & 25,85 \\
\hline \multirow{4}{*}{ DESTO } & 0 & - & - & 6,77 a $\quad(M A)$ & $0,02^{\mathrm{NS}}$ & \\
\hline & 480 & - & - & $2,26 \mathrm{~b} \quad$ (D) & $30,18^{* *}$ & \\
\hline & 960 & - & - & $2,24 \mathrm{~b}(\mathrm{MAxD})$ & $0,01^{\mathrm{NS}}$ & \\
\hline & Média & $3,72 \mathrm{~A}$ & $3,79 \mathrm{~A}$ & & & 40,05 \\
\hline \multirow{4}{*}{ ELEIN } & 0 & $13,20 \mathrm{Aa}$ & $7,10 \mathrm{Ba}$ & 10,15 & $27,40{ }^{\bullet *}$ & \\
\hline & 480 & $2,24 \mathrm{Ab}$ & $2,24 \mathrm{Ab}$ & $2,24 \quad$ (D) & $184,93^{*}$ & \\
\hline & 960 & $2,24 \mathrm{Ab}$ & $2,24 \mathrm{Ab}$ & 2,24 (MAxD) & $27,40^{* *}$ & \\
\hline & Média & 5,89 & 3,86 & - & & 21,79 \\
\hline \multirow{4}{*}{ DIGHO } & 0 & $3,43 \mathrm{Aa}$ & $2,68 \mathrm{Ba}$ & (MA) & $3,53^{\mathrm{NS}}$ & \\
\hline & 480 & $2,24 \mathrm{Ab}$ & $2,24 \mathrm{Aa}$ & $2,24 \quad$ (D) & $16,79^{* *}$ & \\
\hline & 960 & $2,24 \mathrm{Ab}$ & $2,24 \mathrm{Aa}$ & 2,24 (MAxD) & $3,53^{\circ}$ & \\
\hline & Média & 2,63 & 2,38 & - & & 14,56 \\
\hline \multirow{4}{*}{ SIDRH } & 0 & - & - & 7,65 a & $0,02^{\mathrm{NS}}$ & \\
\hline & 480 & - & - & $2,24 \mathrm{~b} \quad$ (D) & $40,65^{* *}$ & \\
\hline & 960 & - & - & $2,24 \mathrm{~b}$ (MAxD) & $0,02^{\mathrm{NS}}$ & \\
\hline & Média & $4,08 \mathrm{~A}$ & $4,00 \mathrm{~A}$ & - & & 38,39 \\
\hline \multirow{4}{*}{ AMARE } & 0 & - & - & 5,44 a $\quad(M A)$ & $2,10^{\mathrm{NS}}$ & \\
\hline & 480 & - & - & $2,24 \mathrm{~b} \quad$ (D) & $11,68^{\circ *}$ & \\
\hline & 960 & - & - & $2,24 \mathrm{~b}(\mathrm{MAxD})$ & $2,10^{\mathrm{NS}}$ & \\
\hline & Média & $3,75 \mathrm{~A}$ & $2,85 \mathrm{~A}$ & & & 51,76 \\
\hline \multirow{4}{*}{ ACNHI } & 0 & - & - & 2,96 a & $13,59^{* *}$ & \\
\hline & 480 & - & - & 2,80 a $\quad$ (D) & $0,69^{\mathrm{NS}}$ & \\
\hline & 960 & - & - & 2,72 a (MAxD) & $1,75^{\mathrm{NS}}$ & \\
\hline & Média & $2,51 \mathrm{~B}$ & $3,14 \mathrm{~A}$ & - & & 16,56 \\
\hline
\end{tabular}

(1) Dados transformados para $\sqrt{(X+0,5)}$.

(2) Médias com a mesma letra năo diferem entre sí pelo teste de Tukey a $5 \%$ de probabilidade, sendo que letras minúsculas comparam efeito das doses e letras maiúsculas comparam os métodos de aplicaçăo.

plantas daninhas, sem, contudo, haver diferenças entre as doses de 480 e $960 \mathrm{~g} / \mathrm{ha}$. O método de aplicação não alterou a eficiência do produto. Quanto ao peso da matéria seca destas espécies aos 60 DAA, os resultados foram idênticos aos da densidade.

Segundo Klein \& Felippe (1991), as sementes de BIDPI, DIGHO e AMARE são fotoblásticas positivas, ou seja, requerem luz para germinar, o que pode explicar o efeito da barreira física imposta pelo papel, reduzindo a germinação das sementes de BIDPI e DIGHO. Este efeito não foi observado na germinação de DESTO, visto que esta espécie é indiferente à luz, além de apresentar dormência, o que explica o elevado coeficiénte de variação, obse rvado para a densidade e matéria seca, e a baixa eficiência do papel como barreira física. No caso das sementes de AMARE, Taylorson (1970) afirma que elas são sensíveis á intensidade luminosa, apresentando porcentagem de germinação diretamente proporcional à intensidade luminosa incidente, fato este não constatado neste trabalho.

No caso específico do capim-pé-de-galinha (ELEIN), observou-se até 60 DAA tanto efeito de dose quanto do método de aplicação, quando a interação destes dois fatores foi significativa. Verificou-se que a cobertura do solo com papel sem o produto veiculado foi suficiente para reduzir a 
TABELA 3 - Efeitos de doses de oxyfluorfen em dois métodos de aplicação sobre a densidade ${ }^{(1)}$ de plantas de BIDPI, DESTO, ELEIN, DIGHO, SIDRH, AMARE, e ACNHI, avaliadas aos 45 DAA. Jaboticabal, 1991.

\begin{tabular}{|c|c|c|c|c|c|c|}
\hline \multirow{2}{*}{ Espécies } & \multirow{2}{*}{$\begin{array}{c}\text { Doses (D) } \\
(\mathrm{g} / \mathrm{ha})\end{array}$} & \multicolumn{2}{|c|}{ Método de Aplicação (MA) } & \multirow{2}{*}{ Média } & \multicolumn{2}{|c|}{ Valores } \\
\hline & & Pulverizado & Veiculado & & $\mathbf{F}$ & $\mathrm{CV}(\%)$ \\
\hline \multirow{4}{*}{ BIDPI } & 0 & - & - & 4,27 a $\quad(M A)$ & $0,61^{\mathrm{NS}}$ & \\
\hline & 480 & - & - & $2,74 \mathrm{~b} \quad$ (D) & $10,12^{* *}$ & \\
\hline & 960 & - & - & $2,38 \mathrm{~b}(\mathrm{MAxD})$ & $1,42^{* *}$ & \\
\hline & Média & $3,27 \mathrm{~A}$ & $2,99 \mathrm{~A}$ & $\cdot$ & & 31,88 \\
\hline \multirow{4}{*}{ DESTO } & 0 & - & - & 4,46 a $\quad(M A)$ & $0,83^{\text {NS }}$ & \\
\hline & 480 & - & - & $2,28 \mathrm{~b} \quad$ (D) & $8,82^{* *}$ & \\
\hline & 960 & - & - & $2,24 \mathrm{~b}(\mathrm{MAxD})$ & $0,69^{\text {NS }}$ & \\
\hline & Média & $2,76 \mathrm{~A}$ & $3,22 \mathrm{~A}$ & & & 45,31 \\
\hline \multirow{4}{*}{ ELEIN } & 0 & $15,16 \mathrm{Aa}^{(2)}$ & $8,33 \mathrm{Ba}$ & $11,74 \quad$ (MA) & $22,43^{* *}$ & \\
\hline & 480 & $2,24 \mathrm{Ab}$ & $2,24 \mathrm{Ab}$ & $2,24 \quad$ (D) & $173,64 *$ & \\
\hline & 960 & $2,24 \mathrm{Ab}$ & $2,24 \mathrm{Ab}$ & 2,24 (MAxD) & $22,43^{* *}$ & \\
\hline & Média & 6,54 & 4,27 & - & & 24,37 \\
\hline \multirow{4}{*}{ DIGHO } & 0 & - & - & 2,82 a $\quad(M A)$ & $2,78^{\mathrm{NS}}$ & \\
\hline & 480 & - & - & $2,24 \mathrm{~b}$ & $23,04^{* *}$ & \\
\hline & 960 & - & - & 2,24 b (MAxD) & $2,78^{\mathrm{NS}}$ & \\
\hline & Média & $2,50 \mathrm{~A}$ & $2,36 \mathrm{~A}$ & $\cdot$ & & 9,11 \\
\hline \multirow{4}{*}{ SIDRH } & 0 & - & - & 7,81 a $\quad$ (MA) & $10,97^{* *}$ & \\
\hline & 480 & - & - & $3,72 \mathrm{~b} \quad$ (D) & $21,46^{* *}$ & \\
\hline & 960 & - & - & $2,24 \mathrm{~b}(\mathrm{MAxD})$ & $3,37^{\mathrm{NS}}$ & \\
\hline & Média & $3,39 \mathrm{~B}$ & $5,78 \mathrm{~A}$ & - & & 42,95 \\
\hline \multirow{4}{*}{ AMARE } & 0 & - & - & 6,50 a $\quad(M A)$ & $1,74^{\mathrm{NS}}$ & \\
\hline & 480 & - & - & $2,24 \mathrm{~b} \quad$ (D) & $11,66^{* *}$ & \\
\hline & 960 & - & - & $2,24 \mathrm{~b}(\mathrm{MAxD})$ & $1,74^{\mathrm{NS}}$ & \\
\hline & Média & $4,20 \mathrm{~A}$ & $3,10 \mathrm{~A}$ & & & 62,13 \\
\hline \multirow{4}{*}{ ACNHI } & 0 & - & - & 3,13 a & $26,43^{* *}$ & \\
\hline & 480 & - & - & $3,30 \mathrm{a} \quad$ (D) & $1,88^{\mathrm{NS}}$ & \\
\hline & 960 & - & - & 2,85 a (MAxD) & $2,87^{\mathrm{NS}}$ & \\
\hline & Média & $2,60 \mathrm{~B}$ & $3,58 \mathrm{~A}$ & - & & 16,77 \\
\hline
\end{tabular}

(1) Dados transformados para $\sqrt{(X+0,5)}$.

(2) Médias com a mesma letra não diferem entre sí pelo teste de Tukey a 5\% de probabilidade, sendo que, letras minúsculas comparam o efeito das doses e letras maiúsculas comparam os métodos de aplicação.

densidade desta espécie. A veiculação do oxyfluorfen no papel acentuou este efeito de redução na densidade, porém, tornando-o igual ao do produto pulverizado. Não se constataram diferenças entre os efeitos das doses. Quanto ao peso da matéria seca de FT FIN, os resultados foram os mesmos observados para densidade. As sementes de ELEIN são fotoblásticas positivas (Kogan Alternan, 1992), o que explica o efeito do papel como barreira física.
Observou-se, aos 30 DAA, que a simples cobertura do solo com papel reduziu a densidade de guanxuma (SIDRH) e, quando se veiculou o oxyfluorfen ao papel, este efeito se acentuou, igualando-se ao do produto pulverizado. Já a partir dos 45 DAA não se constatou mais efeito da interação entre os fatores. Aos 45 DAA só se verificou efeito de doses, que reduziram a densidade da guanxuma, sem haver diferenças entre as doses de 480 e $960 \mathrm{~g} / \mathrm{ha}$. Aos 60 DAA observou-se 
TABELA 4 - Efeito de doses de oxyfluorfen em dois métodos de aplicação, sobre o peso de matéria seca ${ }^{(1)}$ de plantas de BIDPI, DESTO, ELEIN, DIGHO, SIDRH, AMARE e ACNHI, avaliadas aos 60 DAA. Jaboticabal, 1991.

\begin{tabular}{|c|c|c|c|c|c|c|}
\hline \multirow{2}{*}{ Espécies } & \multirow{2}{*}{$\begin{array}{c}\text { Doses (D) } \\
(\mathrm{g} / \mathrm{ha})\end{array}$} & \multicolumn{2}{|c|}{ Método de Aplicaçảo (MA) } & \multirow{2}{*}{ Média } & \multicolumn{2}{|c|}{ Valores } \\
\hline & & Pulverizado & Veiculado & & $\mathbf{F}$ & $\mathrm{CV}(\%)$ \\
\hline \multirow{4}{*}{ BIDPI } & 0 & - & - & 0,65 a $\quad(M A)$ & $1,90^{\mathrm{NS}}$ & \\
\hline & 480 & - & - & $0,44 \mathrm{~b} \quad(\mathrm{D})$ & $9,60^{* *}$ & \\
\hline & 960 & - & - & $0,35 \mathrm{~b}$ (MAxD) & $0,94^{\mathrm{NS}}$ & \\
\hline & Média & $0,52 \mathrm{~A}$ & $0,44 \mathrm{~A}$ & - & & 32,15 \\
\hline \multirow{3}{*}{ DESTO } & 0 & ancte & & 0,68 a $\quad(M A)$ & $0,65^{\mathrm{NS}}$ & \\
\hline & 480 & dis: & & $0,33 \mathrm{~b} \quad$ (D) & $7,57^{* *}$ & \\
\hline & 960 & 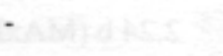 & & $0,32 \mathrm{~b}(\mathrm{MAxD})$ & $0,46^{\mathrm{NS}}$ & \\
\hline \multirow{5}{*}{ ELEIN } & Média & $0,41 \mathrm{~A}$ & $0,48 \mathrm{~A}$ & & & 53,81 \\
\hline & 0 & $3,76 \mathrm{Aa}^{1}$ & $3,01 \mathrm{Ba}$ & 3,38 & $4,20^{\circ}$ & \\
\hline & 480 & $0,32 \mathrm{Ab}$ & $0,32 \mathrm{Ab}$ & 0,32 & $282,11^{* *}$ & \\
\hline & 960 & $0,32 \mathrm{Ab}$ & $0,32 \mathrm{Ab}$ & 0,32 (MAxD) & $4,20^{\circ}$ & \\
\hline & Média & 1,46 & 1,21 & - & & 24,92 \\
\hline \multirow{4}{*}{ DIGHO } & 0 & - & & 1,02 a $\quad(M A)$ & $0,24^{\mathrm{NS}}$ & \\
\hline & 480 & - & - & $0,32 \mathrm{~b} \quad$ (D) & $24,46^{\circ *}$ & \\
\hline & 960 & - & - & $0,32 \mathrm{~b}(\mathrm{MAxD})$ & $0,29^{N S}$ & \\
\hline & Média & $0,57 \mathrm{~A}$ & $0,53 \mathrm{~A}$ & - & & 47,06 \\
\hline \multirow{4}{*}{ SIDRH } & 0 & - & - & 0,76 a $\quad(M A)$ & $4,67^{*}$ & \\
\hline & 480 & - & - & $0,38 \mathrm{~b} \quad$ (D) & $28,43 \cdots$ & \\
\hline & 960 & - & - & $0,32 \mathrm{~b}(\mathrm{MAxD})$ & $1,88^{\mathrm{NS}}$ & \\
\hline & Média & $0,43 \mathrm{~B}$ & $0,54 \mathrm{~A}$ & - & & 29,52 \\
\hline \multirow{3}{*}{ AMARE } & 0 & - & - & 0,93 a $\quad(M A)$ & $0,05^{\mathrm{NS}}$ & \\
\hline & 480 & - & - & $0,32 \mathrm{~b} \quad$ (D) & $18,12^{* *}$ & \\
\hline & 960 & - & - & $0,32 \mathrm{~b}(\mathrm{MAxD})$ & $0,05^{\mathrm{NS}}$ & \\
\hline \multirow{5}{*}{$\mathrm{ACNHI}$} & Média & $0,53 \mathrm{~A}$ & $0,51 \mathrm{~A}$ & & & 50,31 \\
\hline & 0 & - & - & $0,47 \mathrm{a}$ & $13,70^{* *}$ & \\
\hline & 480 & - & - & $0,43 \mathrm{a} \quad$ (D) & $2,39^{\mathrm{NS}}$ & \\
\hline & 960 & - & - & 0,38 a (MAxD) & $1,73^{\mathrm{NS}}$ & \\
\hline & Média & $0,37 \mathrm{~B}$ & $0,49 \mathrm{~A}$ & - & & 20,67 \\
\hline
\end{tabular}

(1) Médias com a mesma letra não diferem entre si pelo teste de Tukey a 5\% de probabilidade, sendo que, letras minúsculas comparam o efeito das doses e letras maiúsculas comparam os métodos de aplicação.

efeito promotor da cobertura do solo com papel sobre a densidade e peso da matéria seca desta espécie, independente da dose de oxyfluorfen utilizada. Por outro lado, verificou-se que as doses de 480 e $960 \mathrm{~g} / \mathrm{ha}$ reduziram a densidade e o peso da matéria seca da guanxuma, sem haver diferenças entre elas e independente do método de aplicação.

No caso do carrapicho-de-carneiro (ACNHI), o oxyfluorfen nas doses de 480 e $960 \mathrm{~g} /$ ha reduziu sua densidade aos 30 DAA, sem se constatar diferenças entre essas doses e os métodos de aplicação. A partir dos 45 DAA verificou-se efeito promotor da cobertura do solo com papel sobre a densidade desta espécie e, aos 60 DAA, sobre o peso da matéria seca. Mas não se constatou mais efeito das doses de oxyfluorfen, ou seja, o produto deixou de controlar esta espécie.

Apesar de sementes de ACNHI serem fotoblásticas positivas (Klein \& Fellipe, 1991), algum efeito secundário provocado pela cobertura do solo com o papel foi o respon- 
sável pelo estímulo da germinação desta espécie. Segundo Kogan Alternan (1992), são vários os fatores que estimulam a quebra de dormência das sementes, o que poderia ter ocorrido neste caso com a cobertura do solo com papel, como, por exemplo, o aumento da umidade e da concentração de etileno, $\mathbf{0}_{2}$ ou $\mathrm{CO}_{2}$ nos primeiros centímetros do solo.

De modo geral, independente do método de aplicação, o oxyfluorfen, nas doses de 480 e 960 g/ha, proporcionou excelente controle de DESTO, ELEIN, DIGHO, SIDRH e AMARE até os 60 DAA. No mesmo período, proporcionou um controle regular de BIDPI, mas não controlou o ACNHI.

O papel, por si só, proporcionou um controle regular de SIDRH até 30 DAA, um bom controle de BIDPI e DIGHO até os 45 DAA e de FI. FIN até 60 DAA, sem contudo controlar DESTO e AMARE. Quanto a ACNHI, a cobertura com papel promoveu sua germinação a partir dos 30 DAA, enquanto com SIDRH este mesmo efeito foi observado aos 60 DAA.

Com relação à suscetibilidade das espécies deste experimento ao herbicida oxyfluorfen, Lorenzi (1986) cita ELFIN e DIGHO como altamente suscetíveis; DESTO, SIDRH e ACNHI como medianamente suscetíveis e BIDPI como pouco suscetível. O autor não cita a espécie AMARE. Almeida \& Rodrigues (1988) citam como susceptíveis DESTO, ELEIN, SIDRH e DIGHO, sem mencionar as demais.

A veiculação do oxyfluorfen no papel não alterou sua eficiência no controle destas sete espécies estudadas neste experimento, o que demonstra ser uma alternativa para aplicação do herbicidaem pré-emergência.

Neste trabalho utilizou-se papel para a veiculação de produtos herbicidas, como sendo uma hipótese de utilização de materiais inertes como veículo destes produtos e se este pode ou não alterar suas propriedades. Os resultados desse trabalho devem ser considerados como um ponto de partida para novos experimentos, nos quais o material utilizado como veículo pode vir a ser subprodutos agrícolas ou indus triais, como casca de arroz ou de amendoim, bagaço de culturas, serragem, entre muitos outros. A viabilidade econômica deste método não foi avaliada neste experimento, mas vai variar em função da disponibilidade do produto a ser utilizado em cada propriedade. Sua utilização prática poderia ser testada em áreas de olericultura e fruticultura, entre outras. A utilização desses materiais inertes, incluindo o papel, necessita de maiores estudos e análises de viabilidade, tendo em vista que poderão tomar-se atraentes em casos específicos.

\section{LITERATURA CITADA}

ALMEIDA, F.S.; RODRIGUES, B.N. Guia de herbicidas. Londrina: IAPAR, 1988. p. 414-420.

KLEIN, A.; FELIPPE, G.M. Efeito da luz na germinação de sementes de ervas invasoras. Pesquisa Agropecuária Brasileira, Brasilia, v. 26, n. 7, p. 955-966, 1991.

KISSMANN, K.G. Plantas infestantes e nocivas. São Paulo: BASF Brasileira, 1992. v.1-2.

KOGAN ALTERNAN, M. Malezas; ecofisiologia y estrategias de control. Santiago: Pontificia Universidad Católica, $1992.402 \mathrm{p}$.

LORENZI, H. Manual de identificação e controle de plantas daninhas. Nova Odessa: H. Lorenzi, 1986.237p.

MOREIRA, M.G. Utilização integrada de cobertura morta pendimethalin ou oxyfluorfen no controle de plantas daninhas nas culturas da alface e da cebola. Jaboticabal: UNESP, 1990. 54p. Trabalho de Graduação em Agronomia.

PRUDENTE, R.M.; MATUO,T. Aplicador de herbicidas com pavio de corda. Primeiros resultados de controle.

Planta Daninha, v. 8, n. 1/2, p. 37-44, 1985.

TAYLORSON, R.B. Changes in dormancy and viability of weed seeds in soils. Weed Science, v. 18, p. 265-270, 1970. 